\title{
KAJIAN KEBUTUHAN PERLINTASAN TIDAK SEBIDANG JALUR KERETA API DENGAN JALAN RAYA DI TITIK PERLINTASAN GANEFO KECAMATAN MRANGGEN
}

\author{
Bambang Sudarmanto \\ Jurusan Teknik Sipil Universitas Semarang (USM) Jl. Soekarno-Hatta Semarang \\ E-mail: bambangsudarmanto68@gmail.com
}

\begin{abstract}
The crossing railway line with the highway is quite a lot in several places in Indonesia, especially on the island of Java. This is a problem in itself because it considers this crossing to have a negative impact on users of land transportation. Moreover, the government does not yet have a policy relating to planning, regulation, supervision and supervision at a level crossing and is discussed with traffic accidents at the intersection of a basic plot to develop systems and procedures at level crossings. The crossing between the Semarang-Purwodadi highway and the Semarang-Surabaya / Solo railway line across the crossing lane on Ganefo still uses a level crossing. In the end, it caused a quite serious problem, namely severe congestion at the time of leaving and returning to work and even frequent traffic accidents. The existence of level crossings at this point is the focus of research by using proposals issued by the Ministry of Attention regarding railway crossings with highways can be made without a door, or can be in a plot with doors equipped, or can be made a plot, according to the research objectives. this is knowing the type of crossing that is right at the crossing of Ganefo. The results of the calculation of the Daily Average Daily Traffic of the Purwodadi-Semarang Directions traffic on the Ganefo pathway found numbers of $15928.2 \mathrm{pcu}$ with the percentage of motorcycle transportation modes (motor cycle) amounting to $87.47 \%$. Whereas the opposite direction, namely Semarang-Purwodadi, is $12784.8 \mathrm{pcu}$ and the percentage of motorbikes is $78.85 \%$ of the total traffic volume. The direct observation of the train journey at the Ganefo crossing point shows the number of train trips that cross the Ganefo as many as 18 trains / day. The average length of the vehicle is at 191,429 meters during peak hours. Charting the criteria for selecting the crossing type of the Ministry of Transportation shows that the crossing point of Ganefo still depends on the position of the point where it is still permitted to use level crossings with safety doors. However, taking into account the increasing number of train trips and considerations of inconvenience and security of road users, this is at risk because depending on the position of the point required the type of crossing is not as large.
\end{abstract}

Keywords; level crossings, annual average daily crossings, train trips

\begin{abstract}
Abstrak
Perlintasan jalur kereta api dengan jalan raya cukup banyak jumlahnya di beberapa tempat di Indonesia, terutama di pulau Jawa. Hal ini menjadi masalah tersendiri karena keberadaan perlintasan ini menimbulkan dampak negatif terhadap pengguna transportasi darat. Terlebih lagi pemerintah belum mempunyai kebijakan yang berkaitan dengan pembinaan (perencanaan, pengaturan, pengawasan dan pengendalian) pada perlintasan sebidang dan kaitannya dengan kecelakaan lalu lintas pada persimpangan sebidang sebagai dasar untuk menyusun sistem dan prosedur di perlintasan sebidang. Perlintasan antara jalan raya Semarang-Purwodadi dan jalur KA Semarang-Surabaya/Solo tepatnya di titik perlintasan yang berada di Ganefo masih menggunakan perlintasan sebidang. Pada kenyataannya, menimbulkan permasalahan yang cukup serius yaitu kemacetan yang parah pada jam berangkat dan pulang kerja dan bahkan sering menimbulkan kecelakaan lalu lintas. Keberadaan perlintasan sebidang di titik inilah yang menjadi fokus penelitian dengan menggunakan kriteria yang dikeluarkan oleh Kementerian Perhubungan mengenai penentuan suatu perlintasan kereta api dengan jalan raya dapat dibuat sebidang tanpa pintu, atau boleh sebidang dengan dilengkapi pintu, atau harus dibuat tidak sebidang, sehingga tujuan dari penelitian ini adalah mengetahui jenis perlintasan yang tepat di perlintasan Ganefo. Hasil dari perhitungan Lintas Harian Rata-Rata Tahunan (LHRT) lalu lintas jalan raya arah Purwodadi-Semarang di lintasan Ganefo ditemukan angka LHRT sebesar $15928.2 \mathrm{smp}$ dengan prosentase moda transport sepeda motor (motor cicle) sebesar $87.47 \%$. Sedangkan arah sebaliknya yaitu Semarang-Purwodadi sebesar $12784.8 \mathrm{smp}$ dan prosentase sepeda motor sebesar $78.85 \%$ dari total volume lalu lintas. Hasil pengamatan langsung perjalanan kereta api di titik perlintasan
\end{abstract}


Ganefo menunjukkan jumlah perjalanan kereta api yang melintasi Ganefo sebanyak 18 kereta/hari. Panjang antrian kendaraan rata rata pada jam sibuk sepanjang 191.429 meter. Ploting grafik kriteria penentuan jenis perlintasan Kementerian Perhubungan menunjukkan titik perlintasan Ganefo masih berada pada posisi titik maksimum masih diperbolehkannya penggunaan perlintasan sebidang dengan pintu pengaman. Akan tetapi, dengan mempertimbangkan peningkatan jumlah perjalanan kereta serta pertimbangan ketidaknyamanan serta keamanan pengguna jalan raya, hal ini menjadi beresiko karena berada pada posisi titik minimum diperlukannya jenis perlintasan tidak sebidang.

Kata Kunci; perlintasan sebidang, lintas harian rata rata tahunan, perjalanan kereta

\section{PENDAHULUAN}

Seiring dengan pesatnya pertumbuhan lalu lintas darat, perlintasan jalur KA dengan jalan raya yang cukup banyak jumlahnya, menjadi masalah tersendiri. Terlebih lagi pemerintah belum mempunyai kebijakan yang berkaitan dengan pembinaan (perencanaan, pengaturan, pengawasan dan pengendalian) pada perlintasan sebidang dan kaitannya dengan kecelakaan lalu lintas pada persimpangan sebidang sebagai dasar untuk menyusun sistem dan prosedur di perlintasan sebidang.

Dalam kurun waktu 2004-2010 terdapat setidaknya 700 Peristiwa Luar Biasa Hebat (PLH), di mana $75 \%$ merupakan kejadian anjlog/terguling, 5\% merupakan tumburan antar KA, dan sisanya merupakan tabrakan kereta dengan kendaraan bermotor pada perlintasan sebidang (Izazaya, 2012). Saat ini, perlintasan antara jalan raya Semarang-Purwodadi dan jalur Kereta Api Semarang-Surabaya masih menggunakan perlintasan sebidang. Pada kenyataannya, titik perlintasan yang berada di Ganefo menimbulkan permasalahan yang cukup serius yaitu kemacetan yang parah pada jam berangkat dan pulang kerja dan bahkan sering menimbulkan kecelakaan lalu lintas. Kemacetan di perlintasan sebidang karena ditutupnya pintu perlintasan untuk mendahulukan perjalanan kereta api sehingga terjadi antrian kendaraan bermotor (Hartono, 2016). Mengingat perkembangan lalu lintas yang sedemikian pesat, maka sudah saatnya dibeberapa titik perlintasan sebidang, khususnya titik perlintasan sebidang Ganefo, perlu dilakukan kajian tentang kelayakan jenis perlintasan tersebut sekaligus rekomendasi jenis perlintasan yang sesuai dan aman bagi pengguna transportasi. Tujuan penelitian ini ialah menemukan jenis perlintasan jalan raya Semarang-Purwodadi dengan Jalan Kereta Api Semarang-Surabaya yang tepat dan aman bagi pengguna lalu lintas di titik perlintasan Ganefo, Kecamatan Mranggen.

\section{METODOLOGI}

Untuk mencapai tujuan tersebut, penelitian dilakukan dengan langkah-langkah menurut diagram alur pada gambar 1 berikut ini.

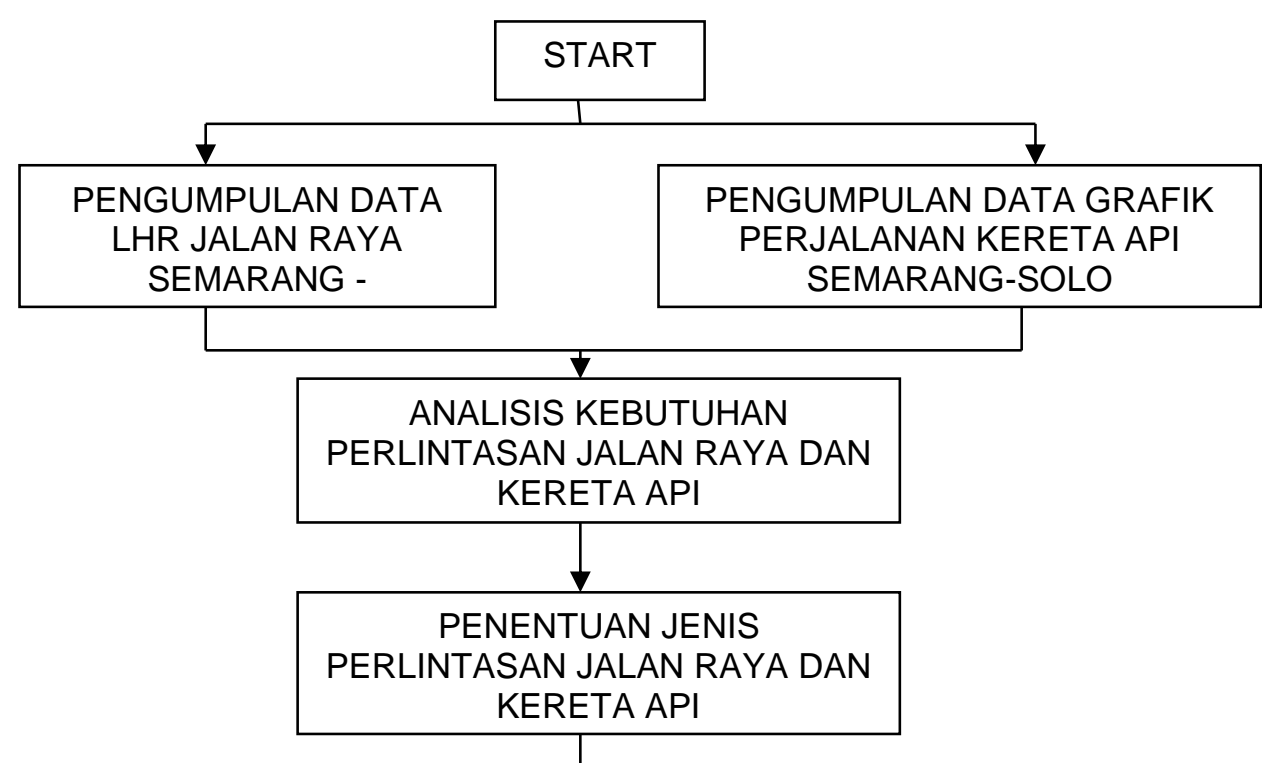


Sumber : Peneliti, 2018

Gambar 1. Diagram Alur Penelitian

\section{ANALISIS DATA}

\section{Lintas Harian Rata-Rata (LHR) Persimpangan Ganefo}

Volume lalu lintas dari pengamatan langsung di lapangan selama satu minggu menunjukkan dominasi kendaraan sepeda motor (motor cycle). Prosentase volume sepeda motor adalah $87.47 \%$ dari total volume lalu lintas dari arah Purwodadi-Semarang. Grafik volume lalu lintas arah Semarang - Purwodadi yang diamati dalam waktu 12 jam mulai pukul 06.00 WIB sampai dengan 18.00 WIB selama satu minggu dapat dilihat pada gambar 2 berikut ini.

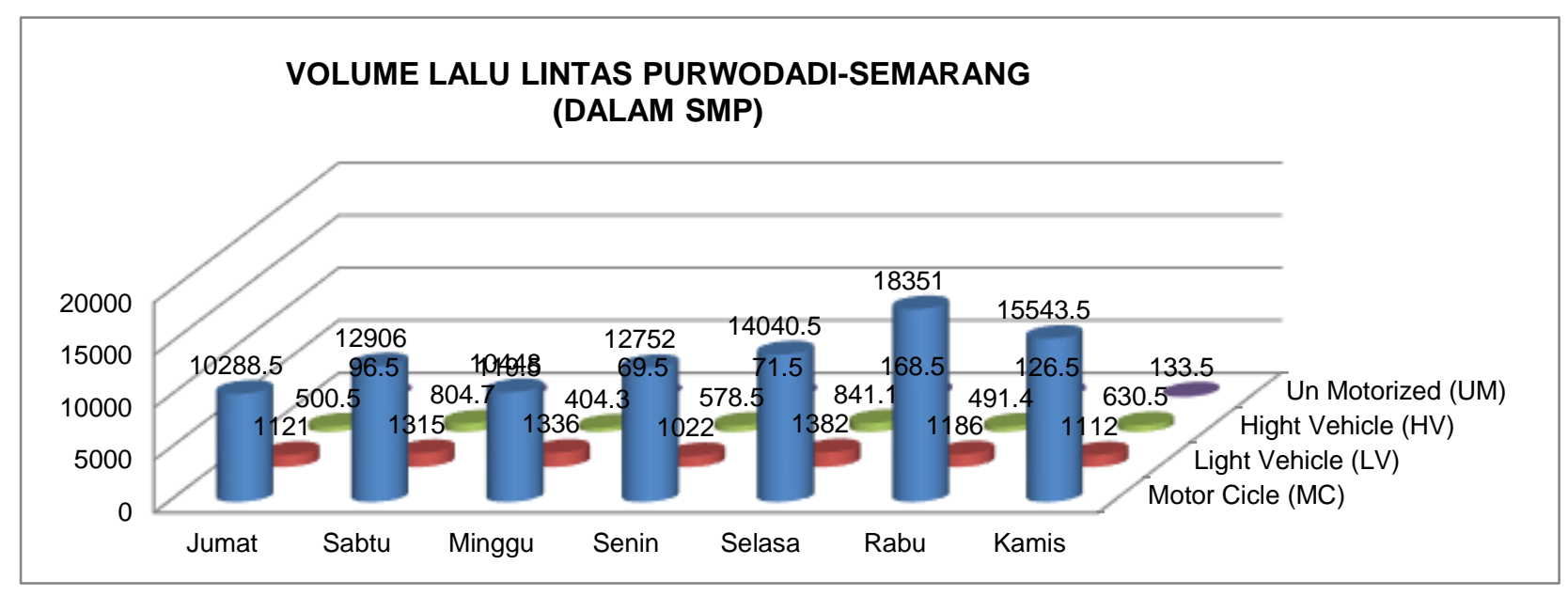

Sumber : Analisis, 2018

\section{Gambar 2. Volume Lalu Lintas Arah Purwodadi-Semarang} Dalam Satuan Mobil Penumpang (SMP)

Sedangkan pada pengamatan volume lalu lintas dari arah Semarang-Purwodadi, prosentase volume sepeda motor adalah $78.85 \%$ dari total volume lalu lintas. Hal ini dapat dilihat pada gambar 3 di bawah ini. 


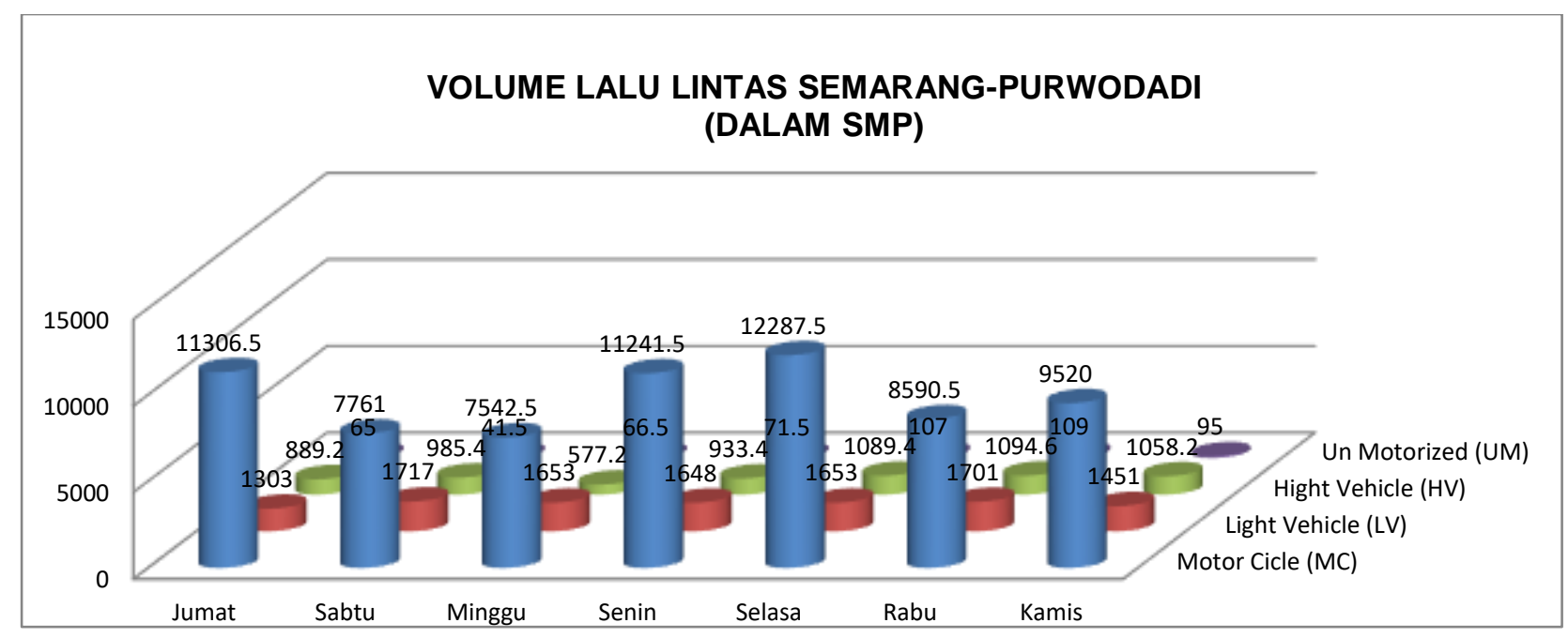

Sumber : Analisis, 2018

\section{Gambar 3. Grafik Volume Lalu Lintas Arah Semarang - Purwodadi Dalam Satuan Mobil Penumpang (SMP)}

Pengamatan pergerakan sepeda motor arah Purwodadi - Semarang, terlihat bahwa volume kendaraan sepeda motor mencapai titik puncak pada jam 16-00 - 17.00 WIB pada hari Selasa dan Rabu. Sebaran arus sepeda motor dalam tiap jam dan tiap hari salam seminggu dapat ditampilkan gambar 4 berikut ini.

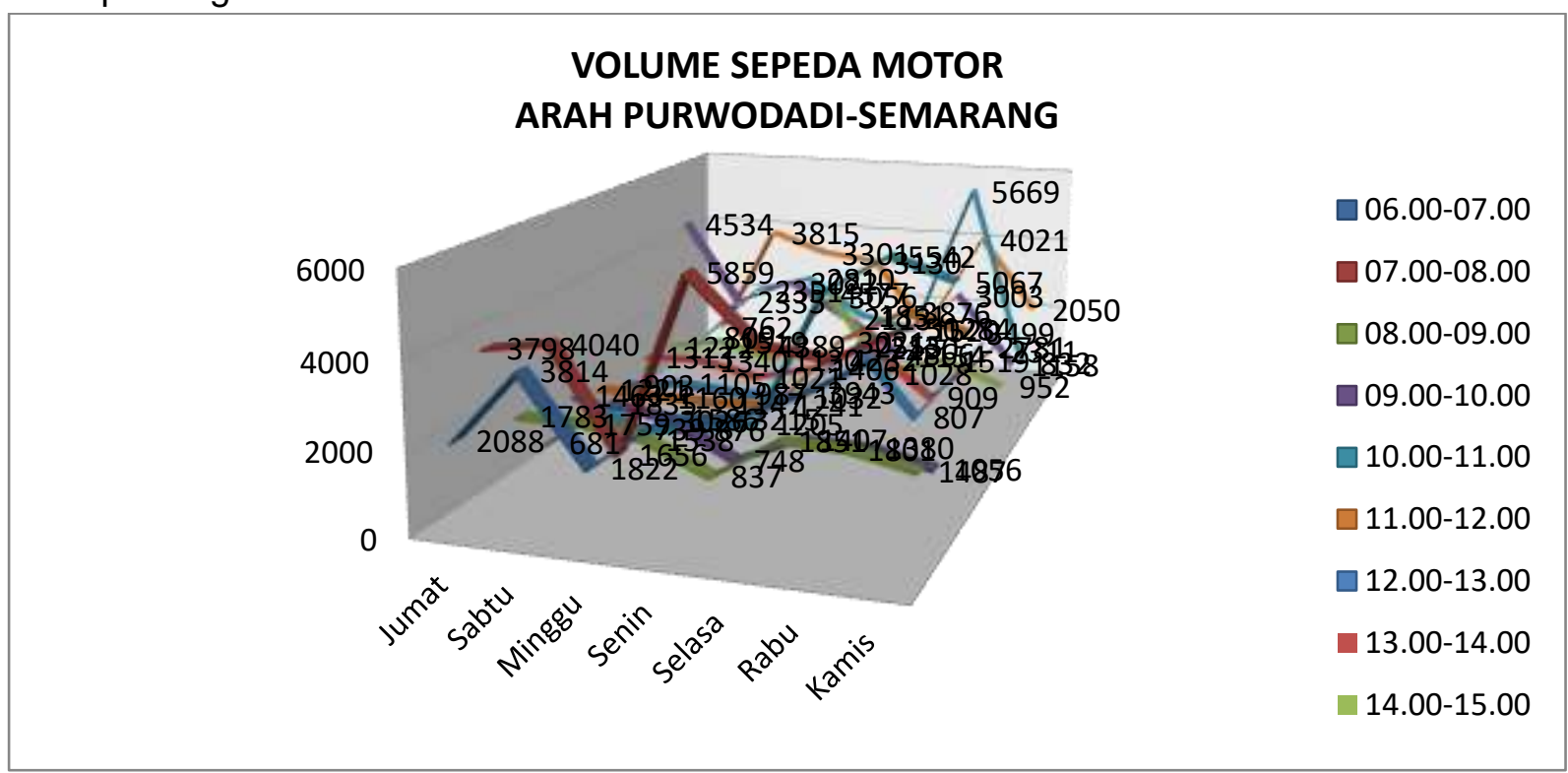

Sumber : Analisis, 2018

\section{Gambar 4. Volume Sepeda Motor arah Purwodadi - Semarang Dalam Jam Pengamatan}

Jam puncak sepeda motor arah Semarang - Purwodadi berbeda dengan jam puncak sepeda motor arah Purwodadi - Semarang. Dari pengamatan di lapangan dapat disimpulkan bahwa jam puncak sepeda motor arah Semarang - Purwodadi terjadi pada jam 16.00 - 17.00 WIB pada hari Jumat, Senin dan Selasa. Sebaran arus sepeda motor dalam tiap jam dan tiap hari dalam seminggu disajikan pada gambar 5 . 


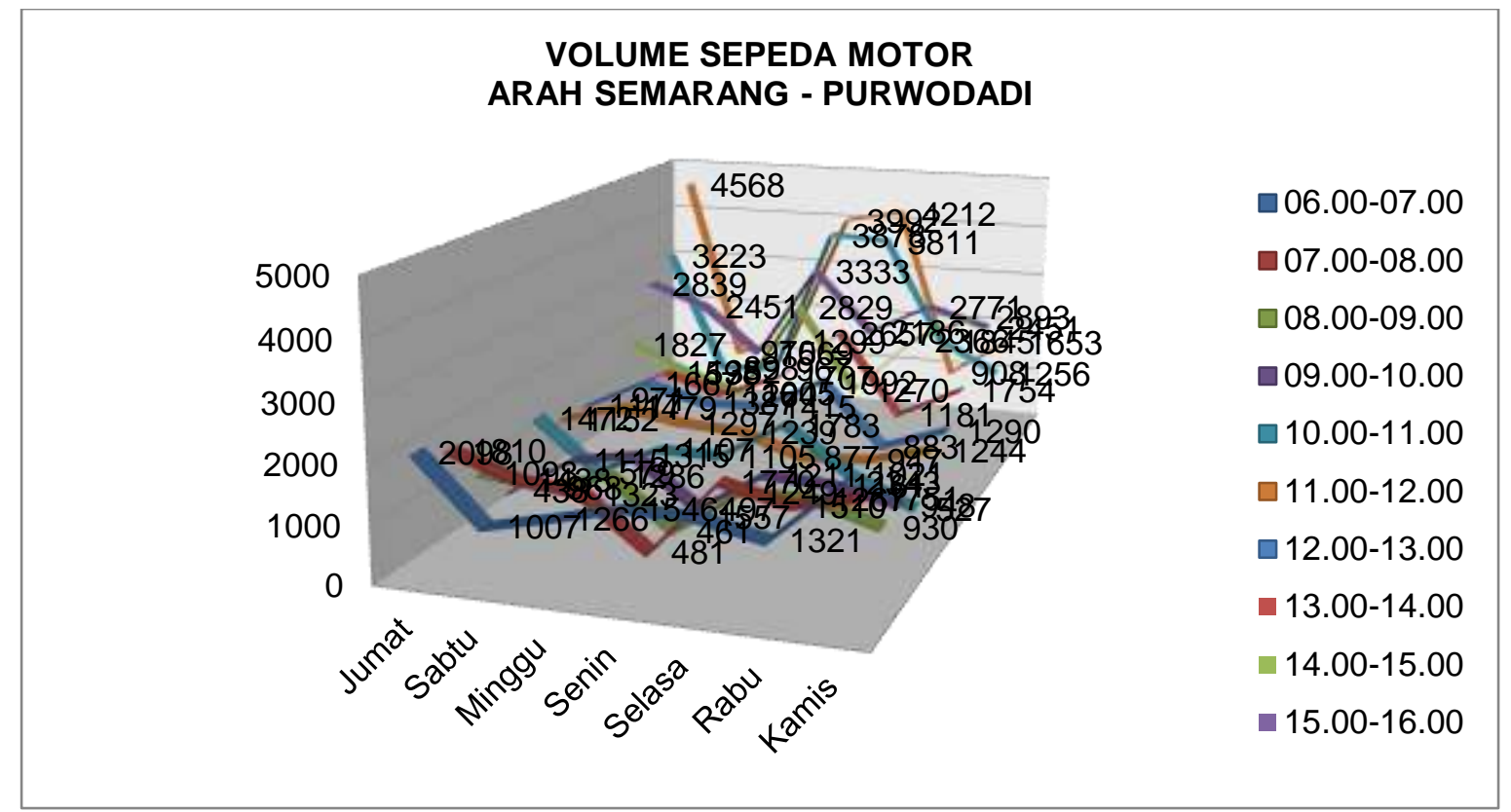

Sumber : Analisis, 2018

\section{Gambar 5. Volume Sepeda Motor arah Semarang - Purwodadi}

\section{Dalam Jam Pengamatan}

Hasil perhitungan LHRT lalu lintas jalan raya Semarang Purwodadi di lintasan Ganefo menunjukkan angka-angka sebagai berikut :

1. Arah Purwodadi-Semarang :

\begin{tabular}{|l|l|}
\hline $\mathrm{Q}=\mathrm{Q} 1+\mathrm{Q} 2+\mathrm{Q} 3+\mathrm{Q} 4+\mathrm{Q} 5+\mathrm{Q} 6+\mathrm{Q} 7$ & 107840 \\
\hline $\mathrm{LMR}=\mathrm{Q} \times 100 / 93$ & 115957 \\
\hline $\mathrm{LHR}=\mathrm{LMR} / 7$ & 16565.3 \\
\hline LHRT $\mathrm{mei}=\mathrm{LHR} \times 100 / 104$ & $\mathbf{1 5 9 2 8 . 2}$ \\
\hline
\end{tabular}

2. Arah Semarang - Purwodadi :

\begin{tabular}{|l|r|}
\hline $\mathrm{Q}=\mathrm{Q} 1+\mathrm{Q} 2+\mathrm{Q} 3+\mathrm{Q} 4+\mathrm{Q} 5+\mathrm{Q} 6+\mathrm{Q} 7=$ & 86558.4 \\
\hline $\mathrm{LMR}=\mathrm{Q} \times 100 / 93=$ & 93073.5 \\
\hline $\mathrm{LHR}=\mathrm{LMR} / 7=$ & 13296.2 \\
\hline LHRT $\mathrm{mei}=\mathrm{LHR} \times 100 / 104=$ & $\mathbf{1 2 7 8 4 . 8}$ \\
\hline
\end{tabular}

\section{Jumlah Perjalanan Kereta Api di Lintasan Kereta Api Ganefo}

Hasil pengamatan langsung perjalanan kereta api di titik perlintasan Ganefo adalah $\mathrm{n}$ sebagai berikut :

1. Jumlah perjalanan kereta api yang melintasi Ganefo adalah $=(14+21+18+19+17+18+15)$ / $7=17.4286$ atau 18 kereta/hari

2. Panjang antrian kendaraan rata rata pada jam sibuk $=(300+300+150+230+100+200+60)$ / 7 = 191.429 meter

\section{Analisis Jenis Perlintasan Yang Sesuai}

Untuk menentukan suatu jenis perlintasan secara kuantitatif maka digunakan kriteria yang dikeluarkan oleh Kementerian Perhubungan mengenai penentuan suatu perlintasan kereta 
api dengan jalan raya dapat dibuat sebidang tanpa pintu, atau boleh sebidang dengan dilengkapi pintu, atau harus dibuat tidak sebidang. Kriteria tersebut menggunakan parameter volume lalu lintas rata-rata harian (kendaraan/hari) dan frekwensi kereta api per hari yang melewati suatu perlintasan sebagai dasar evaluasi yang dinyatakan secara grafis dalam gambar 6.

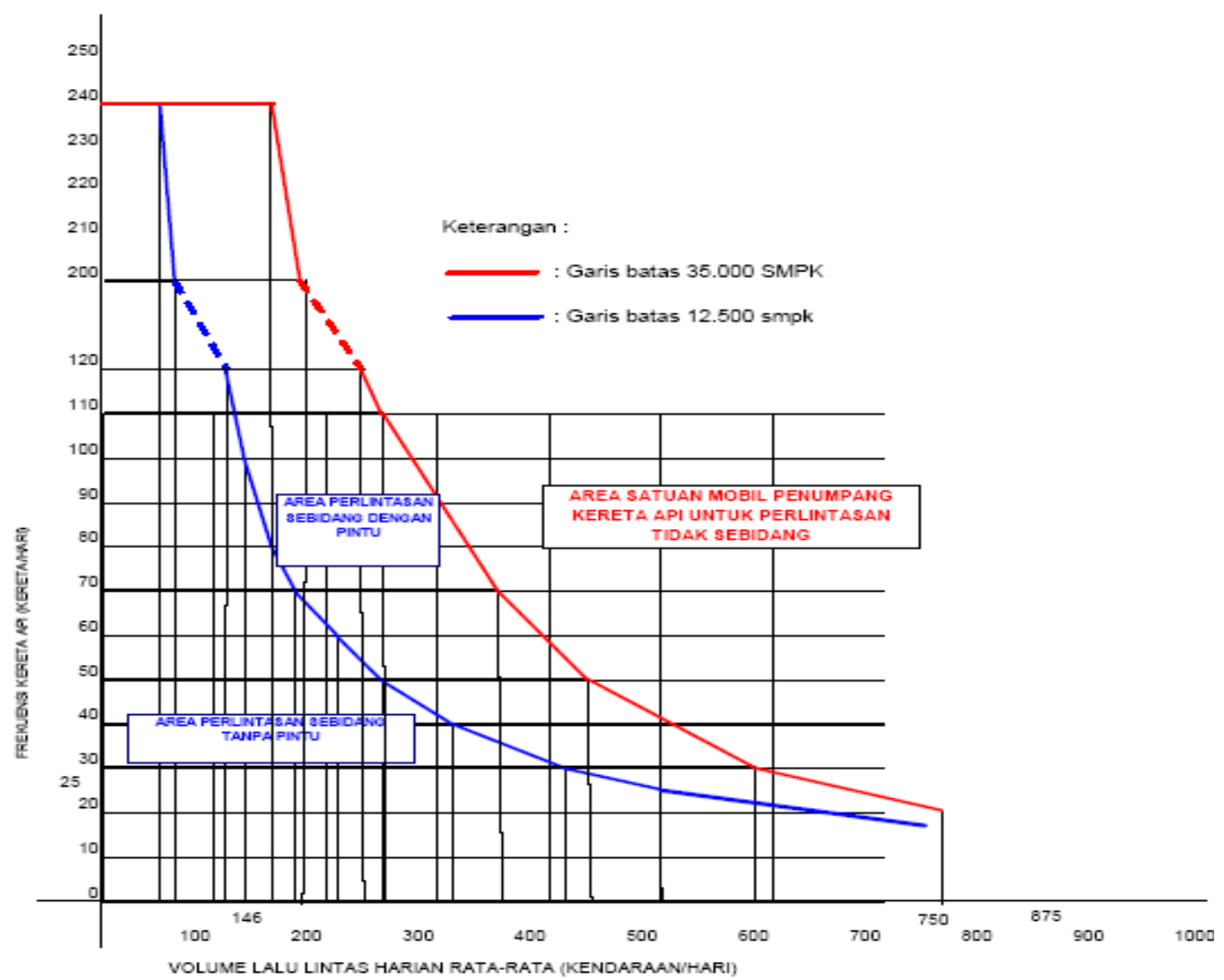

Sumber : Analisis, 2018

Gambar 6. Kriteria Jenis Perlintasan Antara Jalan Raya

Dan Jalan Kereta Api di Titik Perlintasan Ganefo

Dari ploting grafik tersebut didapatkan kesimpulan bahwa titik perlintasan Ganefo masih berada pada posisi diperbolehkan menggunakan perlintasan sebidang dengan pintu pengaman. Akan tetapi, apabila jumlah perjalanan kereta mengalami peningkatan sedikit saja, hal ini menjadi beresiko karena berada pada posisi titik minimum diperlukannya jenis perlintasan tidak sebidang.

Dari pengamatan panjang antrian kendaraan di jalan raya, keberadaan perlintasan sebidang juga sudah sangat mengganggu kenyamanan dan keamanan lalu lintas. Dengan data pengamatan panjang antrian pada jam sibuk yang berada pada angka 191.429 meter, pemilihan perlintasan tak sebidang sudah seharusnya menjadi pilihan pada saat ini.

\section{KESIMPULAN DAN SARAN}

\section{Kesimpulan}

Penelitian dengan judul Kajian Kebutuhan Perlintasan Tidak Sebidang Jalur KA dengan Jalan 
Raya di Titik Perlintasan Ganefo Kecamatan Mranggen memperoleh beberapa data yang dapat dirangkum dalam kesimpulan sebagai berikut :

1. LHRT lalu lintas arah Purwodadi-Semarang adalah $15928.2 \mathrm{smp}$. Komposisi moda transport sepeda motor mencapai $87.47 \%$ dari total volume lalu lintas dan terjadi puncak pada jam 16-00 - 17.00 WIB pada hari Selasa dan Rabu. Sedangkan LHRT lalu lintas arah Semarang - Purwodadi adalah $12784.8 \mathrm{smp}$ dengan prosentase sepeda motor sebesar 78\%. Jam puncak arah Semarang - Purwodadi terjadi pada jam $16.00-17.00$ WIB pada hari Jumat, Senin dan Selasa.

2. Jumlah perjalanan kereta api sebesar $18 \mathrm{kali} / \mathrm{hari}$ dan berada pada titik batas maksimum masih diperbolahkannya jenis perlintasan sebidang. Panjang antrian pada jam sibuk yang berada pada angka 191.429 meter menjadi dasar pertimbangan utama dalam pemilihan perlintasan tak sebidang yang seharusnya menjadi alternatif perlintasan pada saat ini.

3. Titik perlintasan Ganefo berada pada posisi masih diperbolehkan menggunakan perlintasan sebidang dengan pintu pengaman. Akan tetapi jumlah perjalanan kereta api berada pada posisi titik kritis dalam pengertian apabila terjadi penambahan jumlah perjalanan kereta api, titik perlintasan Ganefo sudah harus menggunakan jenis perlintasan tidak sebidang.

\section{Saran}

Dari hasil penelitian ini terdapat beberapa catatan yang cukup penting yang dapat digunakan sebagai tindakan di lapangan dan penelitian lanjutan. Beberapa catatan tersebut adalah sebagai berikut :

1. Keberadaan perlintasan sebidang juga sudah sangat mengganggu kenyamanan dan keamanan lalu lintas dan sudah seharusnya menjadikan pertimbangan untuk segera dibangun perlintasan tidak sebidang pada titik perlintasan kereta api Ganefo.

2. Panjang antrian pada jam sibuk yang berada pada angka yang tidak wajar / angka yang sangat mengganggu kenyamanan berlalu lintas. Hal ini dapat dijadikan bahan kajian tentang tingkat kenyamanan pengguna jalan raya di titik perlintasan Ganefo.

3. Tindak lanjut dari temuan penelitian lainnya adalah diperlukannya penelitian lanjutan dari sisi teknik konstruksi perlintasan tidak sebidang dan penelitian tentang kelayakan penggunaan moda transportasi umum mengingat peluang "demand public transporf" yang cukup terbuka dengan pertimbangan terdapat pola sebaran moda transportasi sepeda motor yang "massif" dan terkonsentrasi dalam jam jam tertentu.

\section{DAFTAR PUSTAKA}

Anonim, (2012), Review Studi Kelayakan Kereta Api Bandara Kuala Namu Milik PT Railink, PT Piesta Dinamika Consult, Jakarta.

Fernando, P. S., Medis S.S., (2013), Studi pengaruh perlintasan Sebidang Jalan Dengan Rel Kereta Api Terhadap Karakteristik Lalu Lintas (Studi Kasus: Perlintasan Kereta Api Jalan Sisingamangaraja Medan), Departemen Teknik Sipil, USU, Medan.

Hartono, (2016), Perlintasan Sebidang Kereta Api di Kota Cirebon, Jurnal Penelitian Transportasi Darat Volume 18, Nomor 1, Maret 2016: 45-62.

Izazaya, E., (2012), Kajian taksonomi kecelakaan kereta api di Indonesia menggunakan Human Factors Analysis and Classification System (HFACS), Tesis Magister Institut Teknologi Bandung, Tidak diterbitkan, Bandung. 
Republik Indonesia, (2013), Kajian Teknis Pembangunan Jalur Ganda Kereta Api Menuju Bandara Kuala Namu, Bahan Paparan Satker Pengembangan Perkeretaapian Sumut, Ditjen Perkeretaapian, Kementerian Perhubungan. 